\title{
Genotyping of B. licheniformis based on a novel multi-locus sequence typing (MLST) scheme
}

\author{
Elisabeth H Madslien ${ }^{1,2}$, Jaran S Olsen ${ }^{1}$, Per E Granum² and Janet M Blatny ${ }^{1 *}$
}

\begin{abstract}
Background: Bacillus licheniformis has for many years been used in the industrial production of enzymes, antibiotics and detergents. However, as a producer of dormant heat-resistant endospores $B$. licheniformis might contaminate semi-preserved foods. The aim of this study was to establish a robust and novel genotyping scheme for $B$. licheniformis in order to reveal the evolutionary history of 53 strains of this species. Furthermore, the genotyping scheme was also investigated for its use to detect food-contaminating strains.

Results: A multi-locus sequence typing (MLST) scheme, based on the sequence of six house-keeping genes (adk, ссрA, recF, rpoB, spoOA and sucC) of 53 B. licheniformis strains from different sources was established. The result of the MLST analysis supported previous findings of two different subgroups (lineages) within this species, named " $A$ " and "B" Statistical analysis of the MLST data indicated a higher rate of recombination within group "A". Food isolates were widely dispersed in the MLST tree and could not be distinguished from the other strains. However, the food contaminating strain B. licheniformis NVH1032, represented by a unique sequence type (ST8), was distantly related to all other strains.
\end{abstract}

Conclusions: In this study, a novel and robust genotyping scheme for B. licheniformis was established, separating the species into two subgroups. This scheme could be used for further studies of evolution and population genetics in B. licheniformis.

\section{Background}

Bacillus licheniformis is a Gram positive, thermophilic spore forming soil bacterium closely related to $B$. subtilis. It is widely used in the fermentation industry for production of enzymes, antibiotics and other chemicals and is generally regarded as a non-pathogen $[1,2]$. However, there are several reports of B. licheniformis- associated human infections such as bacteremia and enocarditis, bovine abortions and food borne diseases which raise the question of its pathogenic potential [39]. More commonly, representatives of this species have caused spoilage of milk, bread and canned foods leading to severe economic losses to the food industry [10-13].

B. licheniformis is ubiquitous in the environment and able to grow under a wide range of temperatures $\left(15-55^{\circ} \mathrm{C}\right)$ in both anaerobic and aerobic conditions making this species a highly potent food contaminant [14-16]. During

\footnotetext{
* Correspondence: Janet-Martha.Blatny@ffi.no

${ }^{1}$ Forsvarets Forskningsinstitutt FFI, Norwegian Defence Research Establishment, P. O. Box 25, Kjeller N-2027, Norway

Full list of author information is available at the end of the article
}

starvation, the cells may form thermo-stabile endospores in a process known as sporulation [17]. These spores are resistant against many decontamination and preservation steps applied by the food industry such as pasteurization, pressure, freezing, extreme $\mathrm{pH}$, radiation and desiccation [18]. In the presence of nutrients (germinants) spores may germinate and grow out into vegetative cells which can multiply in the absence of competing microflora [18,19]. Germination can be further accelerated by external stress such as a short, sublethal heat step (usually at $65-95^{\circ} \mathrm{C}$ ) [20-22]. This phenomenon, known as "activation", is utilized in the "double heat treatment" (a modified tyndallisation), a decontamination strategy where spores that are activated in the primary heat step can be inactivated or killed as germs in the secondary heat treatment [23]. Recent publications have provided new insight into the complexity of spore germination $[20,24,25]$. The observed diversity in germination between and within populations makes spore behavior prediction challenging [26] and might explain why spore decontamination strategies sometimes fail. Detecting

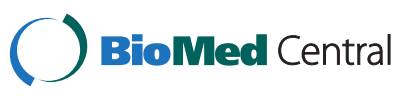


strains with increased potential of causing food spoilage would therefore be of great value to the food industry.

Several molecular typing methods have been applied in order to characterize the population structure within B. licheniformis [27-30]. Multi-locus sequence typing (MLST) has the advantage to other molecular typing methods of being unambiguous and easily portable between laboratories [31]. It has been applied to numerous species including members of the $B$. cereus family and Clostridium spp. [32-36] and has been used for epidemiological purposes identifying strains that could cause human infections $[37,38]$. Basically, it relies on the sequence of several (usually six to eight) conserved house-keeping genes which are independently distributed in the genome. The method is therefore considered to be robust, discriminatory and capable of revealing the deeper evolutionary relation of populations that are studied $[39,40]$. No MLST scheme has so far been developed for B. licheniformis.

The purpose of this study was to establish a MLST scheme for B. licheniformis in order to reveal the evolutionary relationship of 53 strains of this species and to see whether food-contaminating strains were restricted to certain lineages.

\section{Methods}

\section{MLST analysis of $B$. licheniformis}

\section{Strains}

53 strains of B. licheniformis were included in this study. The strains represent various sources, including food, environmental and clinical strains (Figure 1) and were obtained from NVH (Norwegian School of Veterinary Science), CCUG (Culture Collection University of Göteborg, Sweden) and LMG (Laboratorium voor Microbiologie, Universiteit Gent, Belgium). The "F" strains were a kind gift from M. Anderson and M. Salkinoja-Salonen (University of Helsinki, Finland).

\section{Bacterial growth and biochemical identification}

All strains were stored at $-70^{\circ} \mathrm{C}$, plated on sheep blood agar (Columbia blood agar, Oxoid, UK) and grown at $30^{\circ} \mathrm{C}$ overnight. Biochemical characterization was performed on pure cultures by using API $50 \mathrm{CH}$ cassettes (bioMérieux, Marcy l'Etoile, France) according to the instructions given by the manufacturer [41]. Color changes were examined after 24 and $48 \mathrm{~h}$ at $30^{\circ} \mathrm{C}$ and compared to the Bacillus identification profile database, API Lab1 (version 4.0). The reaction profiles of these tests were compared with the Apiweb ${ }^{\mathrm{TM}}$ database provided by the manufacturer.

\section{DNA extraction}

Bacteria were grown on sheep blood agar at $30^{\circ} \mathrm{C}$ overnight. Single colony material was inoculated in $20 \mathrm{ml}$
Luria broth (LB). The bacterial culture was grown overnight at $30^{\circ} \mathrm{C}$ and centrifuged at $3000 \times \mathrm{g}$ for $10 \mathrm{~min}$. The supernatant was discarded and the pellet resuspended in $1 \mathrm{ml}$ enzymatic lysis buffer ( $20 \mathrm{mM}$ Tris.Cl, $\mathrm{pH}$ 8.0, $20 \mathrm{mM}$ Tris.Cl, pH 8.0, $1.2 \%$ Triton $^{\circledR} \mathrm{X}-100$, $20 \mathrm{mg} / \mathrm{ml}$ lysozyme). Further DNA extraction was performed according to the protocol provided by DNeasy Blood and Tissue Kit (Qiagen, USA). The final DNA concentration ranged from $8-72 \mathrm{ng} / \mathrm{ul}$ with a mean 260 / 280 absorbance ratio of 1, 89 (Nanodrop ND-1000 Spectrophotometer, Thermo Fisher Scientific, USA).

\section{MLST scheme}

\section{Primer design}

The MLST scheme was created according to general guidelines described in [42]. Primers were designed to amplify internal fragments of candidate-genes of the publicly available $B$. licheniformis ATCC14580 genome (GenBank: NC_00627) using the Primer3 software [43]. The choice of candidate-genes was based previously published genotyping schemes for members of the Bacillus genus $[28,32,36]$. The primers targeted $400-718$ bp fragments of the nine house-keeping genes $a d k, c c p A$, glpT, gyrB, pyrE, recF, rpoB, sucC and spoOA which were dispersed over the entire genome. The primers targeting rров have been described in a previous publication and was included for comparison [28]. All primers were synthesized by Invitrogen Life Sciences, Norway. Primers and their targets are listed in Table 1 Primers that were used in the final MLST scheme are typed in bold.

\section{Real-time PCR and sequencing}

The nine primer sets were applied on a subset of 20 strains to see which combination of loci that gave the highest level of discrimination and still being congruent (visual evaluation). The amplification reactions were performed in $20 \mu \mathrm{l}$ using $2 \mu \mathrm{l}$ DNA extract (approximately 20 ng of DNA) as a template. Real-time PCR reactions were performed in a LightCycler ${ }^{\circledR} 480$ System using LightCycler ${ }^{\circledR} 480$ SYBR Green I Master (Roche Diagnostics $\mathrm{GmbH}$, Germany) according to recommendations given by the manufacturer of the kit. The temperature program was as follows: $5 \mathrm{~min}$ initial denaturation at $95^{\circ} \mathrm{C}$ followed by 35 cycles of denaturation at $95^{\circ} \mathrm{C}$ for $10 \mathrm{~s}$, annealing at $56^{\circ} \mathrm{C}$ for $10 \mathrm{~s}$ and primer extension at $72^{\circ} \mathrm{C}$ for $30 \mathrm{~s}$. The amplifications were terminated after a final elongation step of $7 \mathrm{~min}$ at $72^{\circ} \mathrm{C}$. The PCR fragments were verified by electrophoresis using Bioanalyzer (Agilent Technologies, USA). PCR products were purified and sequenced by Eurofins MWG Operon (Ebersberg, Germany) using the dideoxy chain termination method on a ABI 3730XL sequencing instrument (Applied Biosystems, USA). 


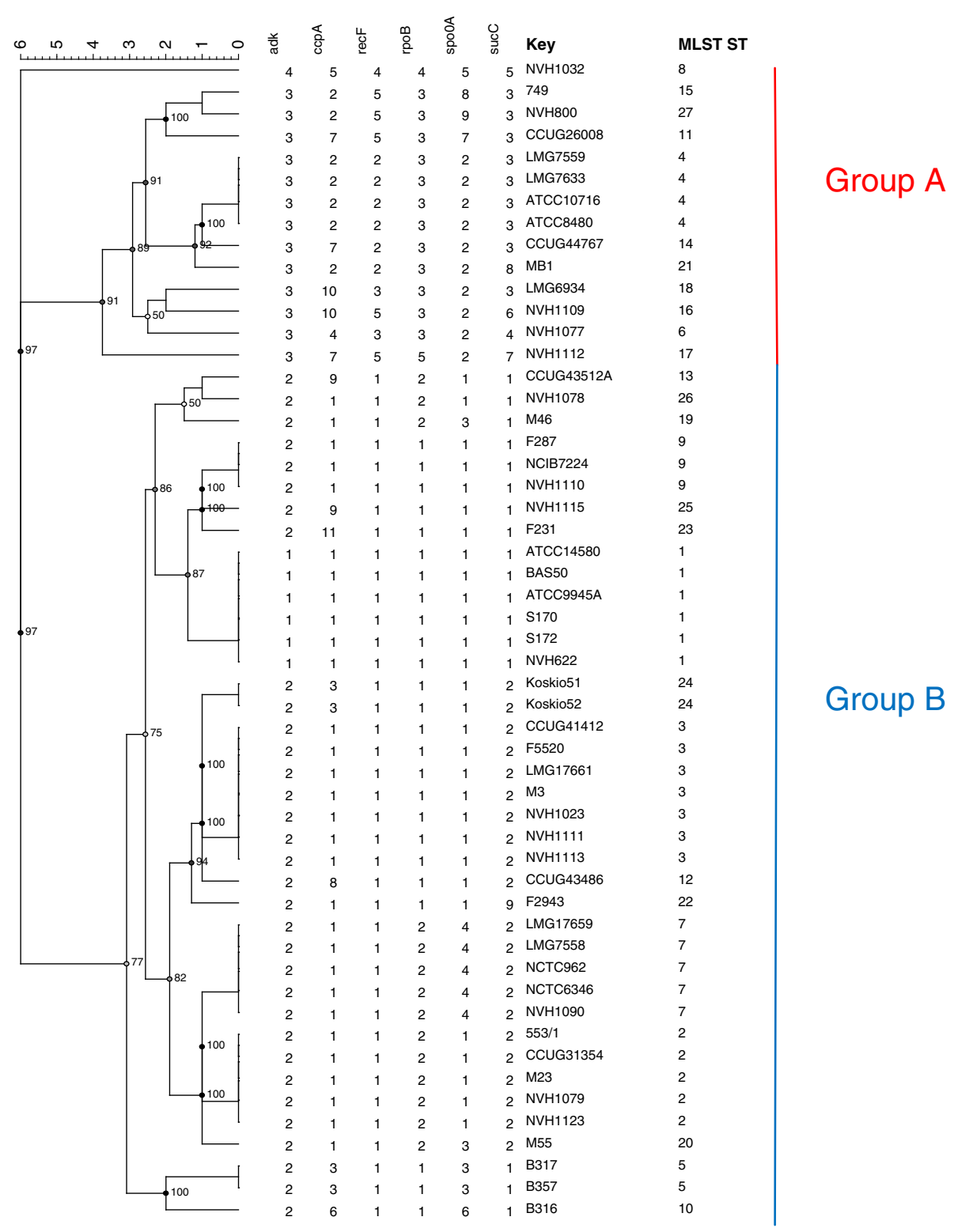

Figure 1 MLST (Multi Locus Sequence Typing) analysis of B. licheniformis. The phylogenetic tree was generated in Bionumerics $v 6.6$ (Applied Maths NV) with the UPGMA (Unweighted Pair Group Method with Arithmetic mean) method on cathegorical numeric data based on the internal fragments of six housekeeping genes. Cophenetic correlations are shown next to the branches.

\section{Data analysis}

The Staden Package [44] was used for alignment, editation and construction of consensus sequences based on the ABI sequence chromatograms. Consensus sequences were entered into the MEGA4 [45] software and aligned by CLUSTALW [46]. Sequences were trimmed to be in frame and encode an exact number of amino acids. Dendograms for each locus (Additional file 1) were constructed in MEGA4 using the Neighbor-Joining method (NJ) with branch lengths estimated by the Maximum Composite Likelihood method $[45,47]$. Branch quality was assessed by the bootstrap test using 500 replicates. A subset of six loci including $a d k, c c p A$, recF, sucC, rpoB and $s p o 0 A$, which gave the highest tree resolution and still being congruent (visual evaluation, Additional file 1), was selected for the final MLST scheme (highlighted in Table 1). The trimmed sequences were entered into BioNumerics software v. 6.6, (Applied Maths NV) as fasta files and used to generate allelic profiles for each isolate based on the six loci. Each unique allelic profile defined a sequence type (ST). A cluster analysis was performed using the allelic profiles as categorical coefficients and a dendogram was constructed based on the UPGMA method. The tree branch quality was estimated by calculating the cophenetic correlation 
Table 1 Primer list

\begin{tabular}{|c|c|c|c|c|}
\hline Primer & Sequence $\left(5^{\prime}-3^{\prime}\right)$ & $\begin{array}{l}\text { Amplicon size } \\
\text { (bp) }\end{array}$ & Target gene (s) & $\begin{array}{l}\text { Target (from-to bp)in } \\
\text { NC_00627 }\end{array}$ \\
\hline adk1L & GGT AAA GGG ACA CAG GCT GA & 518 & BL01030: adk ;adenylate kinase & 144018-144535 \\
\hline adk1R & TCG AGT AAA GGC TGG GTT TG & & & \\
\hline ссрA2L & TAT GAT GTA GCA CGC GAA GC & 604 & BL00444: $c c p A$; transcriptional regulator (compl) & $3007794-3008397$ \\
\hline CcpA4R & TAT CCC CAA GCG CTC TTT TA & & & \\
\hline recF2L & ACG GTT CTG TTC CCA TTC AG & 603 & BL00079: recF; recombination protein $F$ & $3791-4393$ \\
\hline recF2R & CAT CAC GGC CAT TGA CAT AG & & & \\
\hline sucC2L & GGG TCC CGA CGG CCA ACA AA & 595 & BL01285: sucC; succinyl-CoA synthetase, subunit & $1786001-1786595$ \\
\hline $\operatorname{sucC2R}$ & GGC CGG TTC CCC TCC GTA GT & & & \\
\hline rpoB-f & $\begin{array}{l}\text { AGG TCA ACT AGT TCA GTA TGG } \\
\text { ACG [1] }\end{array}$ & 580 & $\begin{array}{l}\text { BL02798: rpoB; DNA-directed RNA polymerase, } \\
\text { subunit beta }\end{array}$ & $120955-121534$ \\
\hline rpoB-r & $\begin{array}{l}\text { AAG AAC CGT AAC CGG CAA } \\
\text { CTT [1] }\end{array}$ & & & \\
\hline spoOA1L & GAA GTG CTT GGT GTC GCA TA & 627 & BL01518: spoOA; response regulator & $2512117-2512743$ \\
\hline spoOA1R & TGT GTA GCC GAA AAG TGA CG & & & \\
\hline pyrE2L & AAA TCA AAG CGG TाT TCC TG & 575 & BL02280: pyrE; orotate phosphoribosyltransferase & 1734961-1735535 \\
\hline pyrETR & AGG ATC CGC TTT CCA TTC TT & & & \\
\hline glpT1L & CTT ACG GGC TGA GCA AGT TC & 593 & BL00185: glpT; glycerol-3-phosphate permease & $4094701-4095293$ \\
\hline glpTiR & CAC GAA AAT GTT GGC AAG TG & & & \\
\hline 3gyrBF & ATC GTT GAG GGT GAC TCT GC & 400 & BL00081:gyrB DNA gyrase subunit B & $6263-6662$ \\
\hline 3gyrBR & AAA TाT CTT CGA GCT GCT GGT & & & \\
\hline
\end{tabular}

coefficients. Sequence analysis was performed using the START2 software package [48] where the number of nucleotide differences and ratio of nonsynonymous to synonymous substitutions $(\mathrm{d} N / \mathrm{d} S)$ were calculated. MEGA5 was used to construct a phylogenetic tree based on the concatenated sequences ( $a d k ; c c p A ; r e c F ; r p o B ; s p o 0 A ; s u c C)$ by the NJ-method with branch lengths estimated by the Maximum Composite Likelihood method [47,49]. Minimum spanning tree (MST) was generated in BioNumerics v.6.6 (Applied Maths NV) using the categorical coefficient.

\section{Index of associaton $\left(I_{A}\right)$}

To test the null hypothesis of linkage equilibrium (alleles are independent) between the alleles of the six MSLT loci, $\mathrm{I}_{\mathrm{A}}$ values were calculated in START2 by the classical (Maynard Smith) and the standardized (Haubold) method [48]. The test was repeated on a dataset containing only one isolate per ST in order to avoid the risk of a bias toward a clonal population for strains with the same epidemiological history (e.g. the abortifacient strains) [35].

\section{Results and discussion \\ MLST analysis}

The percentage of variable sites at each locus ranged from $3.6(s u c C)$ to 7.5 ( $a d k$ ) (Table 2) which is low compared to data obtained for the B. cereus group (several species) but comparable to MLST data for Clostridium septicum $[32,35]$. To our knowledge there are no similar data available for other species within the B. subtilis group which makes relevant comparison difficult. The discriminatory ability of the different loci, measured as number of alleles, varied from four ( $a d k)$ to eleven $(c c p A)$ (Table 3). Despite having the lowest allele

Table 2 Characteristics of $B$. licheniformis MLST loci

\begin{tabular}{|c|c|c|c|c|c|}
\hline Locus & Length of sequenced fragment (bp) & No. of variable sites & $\%$ of variable sites & $\mathrm{dN} / \mathrm{dS}$ ratio & Mean \% GcpC \\
\hline$a d k$ & 465 & 35 & 7,5 & 0.0457 & 44.60 \\
\hline cсpA & 561 & 38 & 6,8 & 0.0090 & 47.79 \\
\hline recF & 561 & 14 & 2,5 & - & 42.49 \\
\hline$r p o B$ & 495 & 13 & 2,6 & - & 44.33 \\
\hline spoOA & 558 & 33 & 5,9 & 0.0043 & 49.93 \\
\hline succ & 549 & 20 & 3,6 & 0.0169 & 47.51 \\
\hline
\end{tabular}


number, a $d k$ represented the least conserved locus, containing the highest frequency of variable sites and also had the highest $\mathrm{d} N / \mathrm{d} S$ nonsynonymous (change of amino acid) to synonymous (no change of amino acid) substitution ratio. In contrast, all of the 14 substitutions in $r e c F$ and 13 substitutions in $r p o B$ were synonymous still providing five different alleles (Table 2 and 3). However, the $d \mathrm{~N} / d \mathrm{~S}$ ratios of all six loci were close to zero, and quite low compared to other studies, indicating that they are all under stabilizing selection $[35,39,50]$. Among the $53 \mathrm{~B}$. licheniformis strains included in this study 27 different sequence types (STs) were identified (Figure 1). 19 STs were represented by only one strain. These strains clustered into two main groups, designated A and B (Figure 1). The strict group division was also consistent within every single locus, as observed by the Neighbor-Joining (NJ) cluster analysis for each individual locus (Additional file 1). Our results corresponded well with previous findings of two different lineages within $B$. licheniformis [28]. The majority of our strains (74\%) including the type strain ATCC14580 clustered into group B. These strains seemed to be more closely related to each other than the strains in group A. No relationship between the source of the isolate and the clustering pattern were found which is in accordance with a previous study based on a combination of different molecular methods, including gyr $A$ and $r p o B$ sequence analysis [28]. Food isolates were found in both groups (Figure 1 and Additional file 2). Apart from NVH1032 (ST8) (contaminant of canned food) and NVH1023 (ST3) (from the same product and manufacturer as NVH1032) we have sparse information about their survival in heat treated foods. Interestingly, NVH1032 was the only strain that did not fall into any of the two main groups in the allel-based MLST tree and could easily be distinguished from the other. NVH1032 (ST8) and to a lesser extent NVH1023 (ST3) were originally isolated from a semi-

Table 3 Allele frequencies

\begin{tabular}{lcccccc}
\hline Allele & adk & ccpA & recF & rpoB & spo0A & sucC \\
\hline $\mathbf{1}$ & 6 & 30 & 39 & 25 & 29 & 17 \\
$\mathbf{2}$ & 33 & 7 & 6 & 14 & 10 & 21 \\
$\mathbf{3}$ & 13 & 4 & 2 & 12 & 4 & 9 \\
$\mathbf{4}$ & 1 & 1 & 1 & 1 & 5 & 1 \\
$\mathbf{5}$ & - & 1 & 5 & 1 & 1 & 1 \\
$\mathbf{6}$ & - & 1 & - & - & 1 & 1 \\
$\mathbf{7}$ & - & 3 & - & - & 1 & 1 \\
$\mathbf{8}$ & - & 1 & - & - & 1 & 1 \\
$\mathbf{9}$ & - & 2 & - & - & 1 & 1 \\
$\mathbf{1 0}$ & - & 2 & - & - & - & - \\
$\mathbf{1 1}$ & - & 1 & - & - & - & - \\
Unique & 4 & 11 & 5 & 5 & 9 & 9 \\
\hline
\end{tabular}

preserved meat product. These particular strains managed to survive a spore-reducing heat treatment regime (a modified tyndallization) [22,23] which had been applied for several years until it failed (Granum, P.E., unpublished results). A huge number of cans with meat product were contaminated in pure culture with NVH1032. We do not know, for sure, why these specific strains managed to survive the double heat treatment. Possible explanations could be; inappropriate spore activation, suboptimal levels of germinants or too short time interval between the two heat treatments to allow sufficient germination (loss of heat resistance) and successive inactivation by the secondary heat step [51,52]. It would be of interest to investigate if there are other strains (apart from NVH1032 and NVH1023) in our collection capable of surviving a similar heat regime and whether this feature is linked to certain genotypes. This would be of valuable information to the food industry.

The clustering of the various $B$. licheniformis strains is visualized in the minimum spanning tree (MST) in Figure 2. The Standardized Index of Association (IA) was significantly different from zero $\left(\mathrm{I}_{\mathrm{A}}^{\mathrm{S}}=0,4365 ; P=0,0000\right)$ indicating a clonal population structure (linkage disequilibrium). These data are consistent with results obtained by MLST analysis of the B. cereus group [32]. Similar results were obtained when calculating IA on a dataset containing only one representative of each ST, showing that potential sampling bias did not affect the outcome of the analysis [35]. Separate calculations for members of group A and B were performed to study any difference within the two subpopulations. Significant linkage disequilibrium was detected in group A $\left(\mathrm{I}_{\mathrm{A}}^{\mathrm{S}}=0,2391 ; P=0,000\right)$, whereas this was not the case in group $B$ where $I_{A}^{S}$ was closer to zero $\left(I_{A}^{S}=0,0113\right.$; $P=0,255)$. These results indicate that members of group $B$ are subject to a higher rate of recombination than group A. We could hypothesise that the clonal structure of subgroup A was due to lack of natural genetic competence as described for DSM13 (isogenic to ATCC14580) [53,54]. Surprisingly, the genetically competent strain NVH1082/ 9945A [55] had identical ST (ST1) to the non-competent type strain ATCC14580, a fact that undermines our hypothesis.

In cases were recombination is rare it is generally recommended to concatenate the sequences before calculating dendograms [56]. This concatenated dendogram corresponded well with the allel-based dendogram and is presented in Additional file 3. A small difference between the allel-based and the concatenated dendogram was observed. NVH1032 (ST8) was positioned slightly closer to group A isolates in the latter. When examining individual loci, NVH1032 (ST8) clustered together with group A for all loci apart from $a d k$. It is therefore reasonable to assume that NVH1032 (ST8) could be regarded as a group 


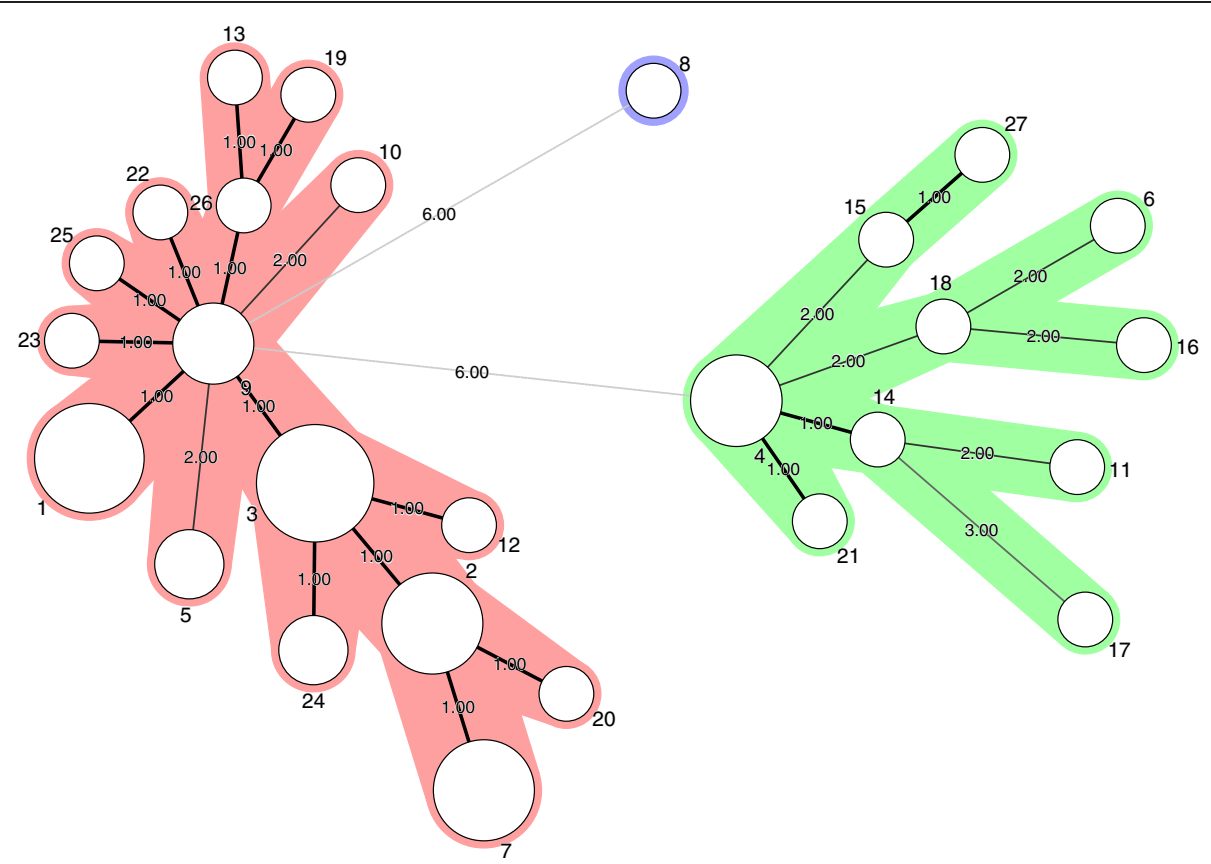

Figure 2 MST (Minimum Spanning Tree) analysis. The network was generated in Bionumerics v. 6.6 (Applied Maths) using character data in default mode. Each circle represents a ST and the type number is indicated next to the circle. The areal of the circle corresponds to the number of strains represented by each ST. Thick solid lines connect STs that differ at only one locus. Thin, solid lines connect STs that differ at two loci. Dotted lines connect STs that differs at three loci. The distances (in terms of number of locus variants) are also indicated next to the branches. STs of group A are coloured green while STs of group B are coloured red.

A member. However, none of the MLST allels of NVH1032 was shared by any other strains in our collection (Additional file 2) underpinning the genetic distinction of NVH1032 (ST8) from the other strains.

\section{Conclusions}

A robust and portable typing scheme for B. licheniformis was established. This method, based on six house-keeping genes separated the species into two distinct lineages. These two lineages seem to have evolved differently. The food spoilage strain NVH1032 was distantly related to all other strains evaluated. The MLST scheme developed in the present study could be used for further studying of evolution and population genetics of $B$. licheniformis.

\section{Additional files}

Additional file 1: Cluster analysis of individual MLST candidate loci. Dendograms of each candidate-locus ( $a d k, c c p A$, glpT, gyrB, pyrE, recF, rpoB, spoOA and sucC) were drawn in MEGA4 using the NJ-method [57]. The quality of each branch is calculated using the bootstrap test with 500 replicates and are shown next to the branches [58]. Branch lengths were estimated using the Maximum Composite Likelihood Method [47].

Additional file 2: Table which shows strain identity, allels, sequence type (ST) and source of the 53 strains that were used in this study. Additional file 3: Concatenated dendogram. The dendogram was constructed in MEGA5 [49] using the NJ-method on the concatenated sequences of the MLST loci (adk, ccpA, recF, rpoB, spoOA and sucC) [57] .
The optimal tree with the sum of branch length 0.0487 is shown. The quality of each branch is calculated using the bootstrap test with 500 replicates and are shown next to the branches [58]. A total of 3189 positions were included in the dataset.

\section{Competing interests}

The authors declare that they have no competing interests.

\section{Authors' contributions}

EHM did the experimental design, carried out the experiments, analysed data and drafted the manuscript. JSO assisted in experimental design, analysed data and assisted in drafting the manuscript. PEG and JMB assisted in experimental design and drafting and reading the manuscript. All authors have read and approved the final manuscript.

\section{Acknowledgements}

We thank Ingjerd Thrane for valuable technical assistance in order to complete this work. The work was supported by grants from the Norwegian Research Council (grant 178299/110) and the Norwegian Defence Research Establishment (FFI).

\section{Author details}

${ }^{1}$ Forsvarets Forskningsinstitutt FFl, Norwegian Defence Research Establishment, P. O. Box 25, Kjeller N-2027, Norway. ${ }^{2}$ Department of Food Safety and Infection Biology, Section for Food Safety, Norwegian School of Veterinary Science, P. O. Box 8146 Dep, Oslo N-0033, Norway.

Received: 22 February 2012 Accepted: 14 September 2012 Published: 10 October 2012

\section{References}

1. Boer AS, Priest F, Diderichsen B: On the industrial use of Bacillus licheniformis: a review. Appl Microbiol Biotechnol 1994, 40:595-598. 
2. Eveleigh DE: The microbiological production of industrial chemicals. Sci Am 1981, 245:120-130

3. Salkinoja-Salonen MS, Vuorio R, Andersson MA, Kampfer P, Andersson MC, Honkanen-Buzalski T, Scoging AC: Toxigenic strains of Bacillus licheniformis related to food poisoning. Appl Environ Microbiol 1999, 65:4637-4645

4. Agerholm JS, Krogh HV, Jensen HE: A retrospective study of bovine abortions associated with Bacillus licheniformis. J Vet Med, Series B 1995, 42:225-234.

5. Blue SR, Singh VR, Saubolle MA: Bacillus licheniformis bacteremia: five cases associated with indwelling central venous catheters. Clin Infect Dis 1995, 20:629.

6. Santini F, Borghetti V, Amalfitano G, Mazzucco A: Bacillus licheniformis prosthetic aortic valve endocarditis. J Clin Microbio/ 1995, 33:3070-3073.

7. Sugar AM, McCloskey RV: Bacillus licheniformis sepsis. JAMA 1977, 238:1180.

8. Tabbara KF, Tarabay N: Bacillus licheniformis corneal ulcer. Am J Ophthalmol 1979, 87:717-719.

9. Haydushka I, Markova N, Vesselina K, Atanassova M: Recurrent sepsis due to Bacillus licheniformis. J Global Infectious Dis 2012, 4:82-83.

10. Thompson JM, Dodd CER, Waites WM: Spoilage of bread by Bacillus. Int Biodeter Biodegr 1993, 32:55-66.

11. Pirttijärvi TSM, Graeffe TH, Salkinoja-Salonen MS: Bacterial contaminants in liquid packaging boards: assessment of potential for food spoilage. J Appl Microbiol 1996, 81:445-458.

12. Heyndrickx M, Scheldeman P: Bacilli Associated with Spoilage in Dairy Products and Other Food. In Applications and systematics of Bacillus and relatives. Edited by Berkeley R. Oxford: Blackwell; 2002:64-82.

13. Sorokulova IB, Reva ON, Smirnov W, Pinchuk IV, Lapa SV, Urdaci MC: Genetic diversity and involvement in bread spoilage of Bacillus strains isolated from flour and ropy bread. Lett Appl Microbiol 2003, 37:169-173.

14. Shariati P, Mitchell WJ, Boyd A, Priest FG: Anaerobic metabolism in Bacillus licheniformis NCIB 6346. Microbiology 1995, 141:1117-1124

15. Clements LD, Miller BS, Streips UN: Comparative growth analysis of the facultative anaerobes Bacillus subtilis, Bacillus licheniformis, and Escherichia coli. Syst Appl Microbiol 2002, 25:284-286.

16. Fields ML, Zamora AF, Bradsher M: Microbial analysis of home-canned tomatoes and green beans. J Food Sci 1977, 42:931-934.

17. Piggot PJ, Hilbert DW: Sporulation of Bacillus subtilis. Curr Opin Microbiol 2004, 7:579-586

18. Setlow P: Spores of Bacillus subtilis: their resistance to and killing by radiation, heat and chemicals. J Appl Microbiol 2006, 101:514-525.

19. Moir A: How do spores germinate? J Appl Microbiol 2006, 101:526-530.

20. Lovdal I: Germination of Bacillus species related to food spoilage and safety, PhD thesis. 2012

21. Paidhungat M, Setlow P: Spore germination and outgrowth. In Bacillus subtilis and its closest relatives: from genes to cells. Edited by Sonenshein AL, Hoch JA, Losick R. Washington, D.C: ASM; 2002:537-548.

22. Keynan A, Evenchik Z: Activation. In The bacterial spore. Edited by Gould GW, Hurst A. New York: Academic Press; 1969:359-396.

23. Brown JV, Wiles R, Prentice G: The effect of a modified tyndallization process upon the spore forming bacteria of milk and cream. J Soc Dairy Technol 1979, 32:109-112.

24. Hornstra LM, Ter Beek A, Smelt JP, Kallemeijn WW, Brul S: On the origin of heterogenity in (preservation) resistance of Bacillus spores: input for a 'systems' analysis approach of bacterial spore outgrowth. Int J Food Microbiol 2009, 134:9-15.

25. Ghosh S, Setlow P: Isolation and characterization of superdormant spores of Bacillus species. J Bacteriol 2008, 191:1787-1797.

26. Brul S, van Beilen J, Caspers M, O Brien A, de Koster C, Oomes S, Smelt J, Kort R, Ter Beek A: Challenges and advances in systems biology analysis of Bacillus spore physiology; molecular differences between an extreme heat resistant spore forming Bacillus subtilis food isolate and a laboratory strain. Food Microbiol 2011, 28:221-227.

27. Duncan KE, Ferguson N, Kimura K, Zhou X, Istock CA: Fine-scale genetic and phenotypic structure in natural populations of Bacillus subtilis and Bacillus licheniformis. Implications for bacterial evolution and speciation. Evolution 1994, 48:2002-2025

28. De Clerck E, De Vos P: Genotypic diversity among Bacillus licheniformis strains from various sources. FEMS Microbiol Lett 2004, 231:91-98.

29. Palmisano MM, Nakamura LK, Duncan KE, Istock CA, Cohan FM: Bacillus sonorensis sp nov., a close relative of Bacillus licheniformis, isolated from soil in the sonoran desert, arizona. Int J Syst Evol Microbiol 2001, 51:1671-1679.

30. Daffonchio D, Borin S, Frova G, Manachini PL, Sorlini C: PCR fingerprinting of whole genomes: the spacers between the $16 \mathrm{~S}$ and $23 \mathrm{~S}$ rRNA genes and of intergenic tRNA gene regions reveal a different intraspecific genomic variability of Bacillus cereus and Bacillus licheniformis. Int I Syst Bacteriol 1998, 48:107-116.

31. Maiden MCJ, Bygraves JA, Feil E, Morelli G, Russell JE, Urwin R, Zhang Q Zhou J, Zurth K, Caugant DA: Multilocus sequence typing: a portable approach to the identification of clones within populations of pathogenic microorganisms. Proc Natl Acad Sci USA 1998, 95:3140-3145.

32. Helgason E, Tourasse NJ, Meisal R, Caugant DA, Kolsto AB: Multilocus sequence typing scheme for bacteria of the Bacillus cereus group. Appl Environ Microbiol 2004, 70:191-201.

33. Jost BH, Trinh HT, Songer JG: Clonal relationships among Clostridium perfringens of porcine origin as determined by multilocus sequence typing. Vet Microbiol 2006, 116:158-165.

34. Lemee L, Bourgeois I, Ruffin E, Collignon A, Lemeland JF, Pons JL: Multilocus sequence analysis and comparative evolution of virulenceassociated genes and housekeeping genes of Clostridium difficile. Microbiology-Sgm 2005, 151:3171-3180.

35. Neumann AP, Rehberger TG: MLST analysis reveals a highly conserved core genome among poultry isolates of Clostridium septicum. Anaerobe 2009, 15:99-106.

36. Olsen JS, Skogan G, Fykse EM, Rawlinson EL, Tomaso H, Granum PE, Blatny JM: Genetic distribution of 295 Bacillus cereus group members based on adk screening in combination with MLST (Multilocus Sequence Typing) used for validating a primer targeting a chromosomal locus in $B$. anthracis. J Microbiol Methods 2007, 71:265-274.

37. Urwin R, Maiden MCJ: Multi-locus sequence typing: a tool for global epidemiology. Trends Microbiol 2003, 11:479-487.

38. Sullivan CB, Diggle MA, Clarke SC: Multilocus sequence typing - data analysis in clinical microbiology and public health. Mol Biotechnol 2005, 29:245-254.

39. Coffey TJ, Pullinger GD, Urwin R, Jolley KA, Wilson SM, Maiden MC, Leigh JA: First insights into the evolution of streptococcus uberis: a multilocus sequence typing scheme that enables investigation of its population biology. Appl Environ Microbiol 2006, 72:1420-1428.

40. Feil EJ, Cooper JE, Grundmann H, Robinson DA, Enright MC, Berendt T, Peacock SJ, Smith JM, Murphy M, Spratt BG, et al: How clonal is Staphylococcus aureus? J Bacteriol 2003, 185:3307-3316.

41. Logan NA, Berkeley RCW: Identification of Bacillus strains using the API system. J Gen Microbiol 1984, 130:1871-1882.

42. Maiden MCJ: Multilocus sequence typing of bacteria. Annu Rev Microbiol 2006, 60:588.

43. Rozen S, Skaletsky H: Primer3 on the WWW for general users and for biologis programmers. Methods Mol Biol 2000, 132:365-386.

44. Staden R: The Staden sequence analysis package. Mol Biotechnol 1996 5:233-241

45. Tamura K, Dudley J, Nei M, Kumar S: MEGA4: molecular evolutionary genetics analysis (MEGA) software version 4.0. Mol Biol Evol 2007, 24:1596-1599

46. Higgins D, Thompson J, Gibson T: CLUSTALW: improving the sensitivity of progressive multiple sequence alignment through sequence weighting, position-specific gap penalties and weight matrix choice. Nucleic Acids Res 1994, 22:4673-4680.

47. Tamura K, Noi M, Kumar S: Prospects for inferring very large phylogenies by using the neighbour-joining method. Proc Natl Acad Sci 2004 101:11030-11035.

48. Jolley KA, Feil EJ, Chan MS, Maiden MC: Sequence type analysis and recombinational tests (START). Bioinformatics 2001, 17:1230-1231.

49. Tamura K, Peterson D, Peterson N, Stecher G, Nei M, Kumar S: MEGA5: molecular evolutionary genetics analysis using maximum likelihood, evolutionary distance, and maximum parsimony methods. Mol Biol Evol 2011, 28:2731-2739.

50. Kotetishvili M, Kreger A, Auters G, Orris JG Jr, Ulakvelidze A, Tine OC: Multilocus sequence typing for studying genetic relationships among Yersinia species. J Clin Microbiol 2005, 43:2674-2684.

51. Lovdal IS, Hovda MB, Granum PE, Rosnes JT: Promoting Bacillus cereus spore germination for subsequent inactivation by mild heat treatment. J Food Prot 2011, 74:2079-2089. 
52. Ghosh S, Zhang P, Li Y, Setlow P: Superdormant spores of Bacillus species have elevated wet-heat resistance and temperature requirements for heat activation. J Bacterio/ 2009, 191:5584-5591.

53. Hoffmann K, Wollherr A, Larsen M, Rachinger M, Liesegang H, Ehrenreich A, Meinhardt F: Facilitation of direct conditional knockout of essential genes in Bacillus licheniformis DSM13 by comparative genetic analysis and manipulation of genetic competence. Appl Environ Microbiol 2010, 76:5046-5057.

54. Waschkau B, Waldeck J, Wieland S, Eichstädt R, Meinhardt F: Generation of readily transformable Bacillus licheniformis mutants. Appl Microbiol Biotechnol 2008, 78:181-188.

55. Thorne $C B$, Stull HB: Factors affecting transformation in Bacillus licheniformis. J Bacteriol 1966, 91:1012-1020.

56. Maiden MC: Multilocus sequence typing of bacteria. Annu Rev Microbiol 2006, 60:561-588.

57. Saitou N, Nei M: The neighbor-joining method: a new method for reconstructing phylogenetic trees. Mol Biol Evol 1987, 4:406-425.

58. Felsenstein J: Confidence limits on phylogenies: an approach using the bootstrap. Evolution 1985, 39:783-791.

doi:10.1186/1471-2180-12-230

Cite this article as: Madslien et al:: Genotyping of $B$. licheniformis based on a novel multi-locus sequence typing (MLST) scheme. BMC Microbiology 2012 12:230.

\section{Submit your next manuscript to BioMed Central and take full advantage of:}

- Convenient online submission

- Thorough peer review

- No space constraints or color figure charges

- Immediate publication on acceptance

- Inclusion in PubMed, CAS, Scopus and Google Scholar

- Research which is freely available for redistribution 